\title{
PENERAPAN ACCUPRESSUREE PADA TITIK MERIDIAN SP 6 DAN BL 67 TERHADAP LAMA PERSALINAN KALA I
}

\author{
Sa'adah Mujahidah ${ }^{1}$, Novita Sari ${ }^{2}$ \\ ${ }^{1,2}$ Program Studi Profesi Bidan Stikes Karya Husada Semarang, Jl. R. Soekanto No.46, Sambiroto, Kec. \\ Tembalang, Kota Semarang, Jawa Tengah 50276 \\ *Email korespondensi: saadah.mujahidah16@gmail.com \\ (Diterima 02-05-2020; disetujui 09-05-2020; dipublish 27-05-2020)
}

\begin{abstract}
ABSTRAK
Persalinan adalah proses pengeluaran janin yang terjadi selama kehamilan cukup bulan (37-42 minggu), lahir spontan dengan presentasi belakang kepala yang berlangsung selama 18 jam untuk primigravida tanpa tindakan, dan 7-8 jam untuk multigravida tanpa tindakan serta tampa komplikasi . Indonesia termasuk dari 10 negara yang bertanggung jawab atas sekitar 60\% kematian ibu. Data WHO pada tahun 2017 menyatakan bahwa komplikasi utama yang menyebabkan hampir 75\% dari semua kematian ibu adalah perdarahan berat (kebanyakan perdarahan setelah melahirkan), infeksi (biasanya setelah melahirkan), tekanan darah tinggi selama kehamilan (pre-eklampsia dan eklampsia), komplikasi dari aborsi persalinan tidak aman. Hasil survei menemukan bahwa proses kelahiran yang lama dapat menyebabkan keadaan darurat pada ibu dan bayi. Accupressuree adalah teknik noninvasive pengobatan tradisional berasal dari Cina yang bermanfaat untuk menginduksi persalinan dan mengelola nyeri persalinan, lama persalinan kala I. Penelitian ini dilakukan di Puskesmas Halmahera menggunakan desain studi deskriptif dengan metode potong lintang. Subjek penelitian adalah Ibu bersalin primipara di Puskesmas Halmahera yang berada dalam kala I fase aktif (pembukaan 4-10 cm). Teknik sampling dalam penelitian ini adalah non probability sampling jenis accidental sampling, dengan total responden sebanyak 20 orang. Hasil penelitian menunjukkan bahwa rata-rata lama kala I responden adalah $(5,0 \pm 0,795)$ jam dengan rentang lama kala I adalah 4- 6 jam dimana dapat disimpulkan bahwa accupresure pada titik meridian Sp6 dan BL 67 dapat mempercepat lama persalinan kala I Fase aktif pada ibu primigravida sebanyak 1-2 jam.
\end{abstract}

Kata kunci: accupresure, Sp6, BL67, persalinan

\begin{abstract}
Childbirth is a process of fetal expulsion that occurs during term pregnancy (37-42 weeks), spontaneous birth with a back of the head presentation that lasts 18 hours for primigravida without action, and 7-8 hours for multigravida without action and without complications. Indonesia is among the 10 countries responsible for around $60 \%$ of maternal deaths. WHO data in 2017 states that the main complications that cause almost $75 \%$ of all maternal deaths are heavy bleeding (mostly bleeding after childbirth), infections (usually after childbirth), high blood pressure during pregnancy (preeclampsia and eclampsia), complications from unsafe labor abortion. The survey results found that the long birth process can cause emergencies in both mother and baby. Acupressure is a noninvasive technique of traditional medicine originating from China that is useful for inducing labor and managing labor pain, the length of labor in the first stage. This research was conducted at the Halmahera Health Center using a descriptive study design with a cross-sectional method. Subjects were primiparous mothers in Halmahera Health Center which were in the first phase of the active phase (opening 4-10 cm). The sampling technique in this study was a non-probability sampling type of accidental sampling, with a total of 20 respondents. The results showed that the average length of time the respondent I was $(5.0 \pm 0.795)$ hours with a span of time the first time I was 4-6 hours which can be concluded that acupressure at the meridian points Sp6 and BL 67 can accelerate the length of labor when the active phase I in primigravida mothers for 1-2 hours.
\end{abstract}

Keywords: Acupressure, Sp6, BL67, labor 


\section{PENDAHULUAN}

Persalinan adalah proses pengeluaran janin yang terjadi selama kehamilan cukup bulan (37-42 minggu), lahir spontan dengan presentasi belakang kepala yang berlangsung selama 18 jam untuk primigravida tanpa tindakan, dan 7-8 jam untuk multigravida tanpa tindakan serta tampa komplikasi [1-3]. WHO pada tahun 2018 menunjukkan AKI di dunia yaitu 289.000 jiwa. Ini berarti ada 791 ibu meninggal setiap harinya. Amerika Serikat yaitu 3.900 jiwa, Afrika Utara 179.000 jiwa, dan Asia Tenggara 16.000 jiwa. Jumlah kematian ibu di Indonesia masih tergolong tinggi di antara negara-negara ASEAN lainnya yaitu Indonesia 306 per $100.000 \mathrm{KH}$, Filipina 221 per $100.000 \mathrm{KH}$, Vietnam 69 per $100.000 \mathrm{KH}$, Brunei 60 per $100.000 \mathrm{KH}$, Thailand 25 per $100.000 \mathrm{KH}$, dan Malaysia 24 per $100.000 \mathrm{KH}$ [4].

Indonesia termasuk dari 10 negara yang bertanggung jawab atas sekitar 60\% kematian ibu [5]. Survei Demografi Kesehatan Indonesia (SDKI) pada tahun 2017 juga mencatat bahwa persalinan lama dengan $42,96 \%$ adalah penyebab utama kematian ibu dan perinatal diikuti oleh perdarahan $35,26 \%$, dan eklampsia $16,44 \%$ [6].

Data WHO pada tahun 2017 menyatakan bahwa komplikasi utama yang menyebabkan hampir $75 \%$ dari semua kematian ibu adalah perdarahan berat (kebanyakan perdarahan setelah melahirkan), infeksi (biasanya setelah melahirkan), tekanan darah tinggi selama kehamilan (preeklampsia dan eklampsia), komplikasi dari aborsi persalinan tidak aman. Hasil survei menemukan bahwa proses kelahiran yang lama dapat menyebabkan keadaan darurat pada ibu dan bayi, pada ibu dapat terjadi perdarahan dan syok, pada bayi dapat terjadi gawat janin, asfiksia, dan sakit kepala. Ini menggambarkan pentingnya bantuan dengan tenaga kesehatan terlatih karena sebagian besar komplikasi terjadi selama persalinan [7].

Persalinan lama masih merupakan salah satu penyebab kematian ibu. Insiden persalinan lama menurut penelitian $8-9 \%$ [8]. Faktor-faktor yang mempengaruhi lamanya persalinan meliputi faktor ibu, faktor janin, dan factor jalan lahir [9]. Persalinan lama dipengaruhi psikologis ibu presepsi rasa nyeri saat persalinan dapat menimbulkan rasa strees sehingga menyebabkan pelepasan hormon yang berlebihan yaitu kotekolamin dan steroid. Hormon ini dapat menyebabkan ketegangan otot polos vasokonstriksi pembuluh darah sehingga menurunkan kontraksi uterus, penurunan sirkulasi uteroplasenta, pengurangan aliran darah dan oksigen ke uterus, serta timbulnya iskemia membuat impuls nyeri bertambah [10]. Pada primipara lama persalinan pada kala I mempunyai durasi yang lebih lama dibandingkan dengan multipara, dimana lama persalinan kala I pada primigravida berlangsung kira-kira 13 jam, sedangkan pada multigravida kira-kira 7 jam. Lamanya persalinan kala satu pada primipara ini menyebabkan rasa nyeri yang dialami juga lebih lama sehingga resiko mengalami keletihan akan lebih besar yang berakibat pada respon emosi berupa cemas, tegang, takut bahkan panik. Hal tersebut 
Penerapan Accupressuree Pada Titik Meridian SP 6 Dan Bl 67 Terhadap Lama Persalinan Kala I

menunjukkan bahwa pada primipara partus lama dan kematian bayi mempunyai risiko yang lebih besar dibanding pada multipara [11].

Banyak metode yang digunakan untuk induksi persalinan yaitu menggunakan metode farmakologi maupun secara non farmakologi. Penggunaan metode faramakologi yaitu, oksitosin, prostaglandin, misoprostol dll. Sedangkan penggunaan metode non farmakologi yaitu meliputi brithingball, hynobirthing, terapi musik, Accupressure dll. Accupressuree dapat memudahkan proses persalinan karena meningkatkan efektivitas kontraksi pada uterus. Accupressuree juga membantu memproduksi hormon endorpine yang berfungsi mengurangi rasa sakit. Metode ini tidak memiliki efek samping atau kerugian pada pasien dan dapat dilakukan oleh bidan, perawat maupun suami selama persalinan [12]. Accupressuree adalah teknik noninvasive pengobatan tradisional berasal dari Cina yang bermanfaat untuk menginduksi persalinan dan mengelola nyeri persalinan, lama persalinan kala I. Accupressure ilmu penyembuhan yang didasarkan pada keseimbangan antara yin dan yang serta dianggap sebagai saluran energy [13].

Accupressure yang di gunakan untuk induksi persalinan diantaranya adalah Sp6 dan B167. Accupressure titik ini diyakini untk merangsang melepaskan oksitosin dari pituitary yang ada pada gilirannya merangsang kontraksi rahim untuk meningkatkan proses persalinan dan mengelola nyeri persalinan $[13,14]$.
Accupressure pada titik ini diyakini untuk merangsang melepaskan ositosin dan kelenjar pituitary yang dapat merangsang kontraksi rahim untuk meningkatkan proses persalinan atau mengelola nyeri persalinan dalam konteks dukungan sosial analagesia dan epidural tidak tersedia [15]. Teknik accupressure sebagai salah satu metode non farmakologi diharapkan dapat membantu bidan dalam persiapan ibu dan keluarga menghadapi persalinan sehingga kebutuhan ibu selama persalinan untuk mendapatkan pengalaman yang menyenangkan dengan rasa nyeri yang minimal dapat terpenuhi $[15,16]$.

\section{METODE PENELITIAN}

Penelitian ini dilakukan di Puskesmas Halmahera menggunakan desain studi deskriptif dengan metode potong lintang, pada bulan Desember 2019. Subjek penelitian adalah Ibu bersalin primipara di Puskesmas Halmahera yang berada dalam kala I fase aktif (pembukaan 4-10 cm). Teknik sampling dalam penelitian ini adalah non probability sampling jenis accidental sampling, dengan total responen sebanyak 20 orang. Alat ukur dalam penelitian ini menggunakan lembar observasi dan partograf untuk memantau kemajuan persalinan serta stopwach.

\section{HASIL PENELITIAN DAN \\ PEMBAHASAN}

\section{Hasil Penelitian}

Karakteristik responden dalam penelitian ini meliputi usia, paritas, pendidikan yang mana dapat dilihat pada tabel 1. 
Tabel 1

Karakteristik Responden

\begin{tabular}{|c|c|c|c|c|c|}
\hline Karakteristik & Frekuensi & $\begin{array}{c}\text { Persentase } \\
(\%)\end{array}$ & Min & $\operatorname{Max}$ & $\begin{array}{l}\text { Mean } \\
\pm \text { SD }\end{array}$ \\
\hline $\begin{array}{l}\text { Usia } \\
<20 \text { th } \\
20-35 \text { th } \\
>35 \text { th }\end{array}$ & $\begin{array}{l}- \\
18 \\
2\end{array}$ & $\begin{array}{l}- \\
90 \\
10\end{array}$ & 21 & 38 & $\begin{array}{c}29,45 \\
\pm \\
4,382\end{array}$ \\
\hline $\begin{array}{l}\text { Pendidikan } \\
\text { SD } \\
\text { SMP } \\
\text { SMA } \\
\text { Diploma } \\
\text { Sarjana } \\
\text { Magister } \\
\end{array}$ & $\begin{array}{l}2 \\
8 \\
3 \\
2 \\
3 \\
2 \\
\end{array}$ & $\begin{array}{l}10 \\
40 \\
15 \\
10 \\
15 \\
10\end{array}$ & 2 & 7 & $\begin{array}{c}4,10 \\
\pm \\
1,586\end{array}$ \\
\hline $\begin{array}{l}\text { Lama Kala I } \\
<6 \text { jam } \\
\geq 6 \text { jam }\end{array}$ & $\begin{array}{l}14 \\
6\end{array}$ & $\begin{array}{l}70 \\
30\end{array}$ & 4 & 6 & $\begin{array}{l}5,0 \pm \\
0,795\end{array}$ \\
\hline
\end{tabular}

Berdasarkan tabel 1 dapat dilihat dari sebanyak 20 orang subjek yang diteliti bahwa karakteristik usia responden nilai rata-ratanya adalah $(29,45 \pm 4,382)$ tahun dengan rentang umur responden adalah 21- 38 tahun. Pendidikan rata-rata responden adalah $(4,10 \pm 1,586)$ dengan rentang pendidikan SD-Magister. Rata-rata lama kala I responden adalah $(5,0 \pm 0,795)$ jam dengan rentang lama kala I adalah 4- 6 jam.

Gambaran pengukuran lama Kala I Persalinan Fase Aktif ini ditunjukkan dengan Gambar1.

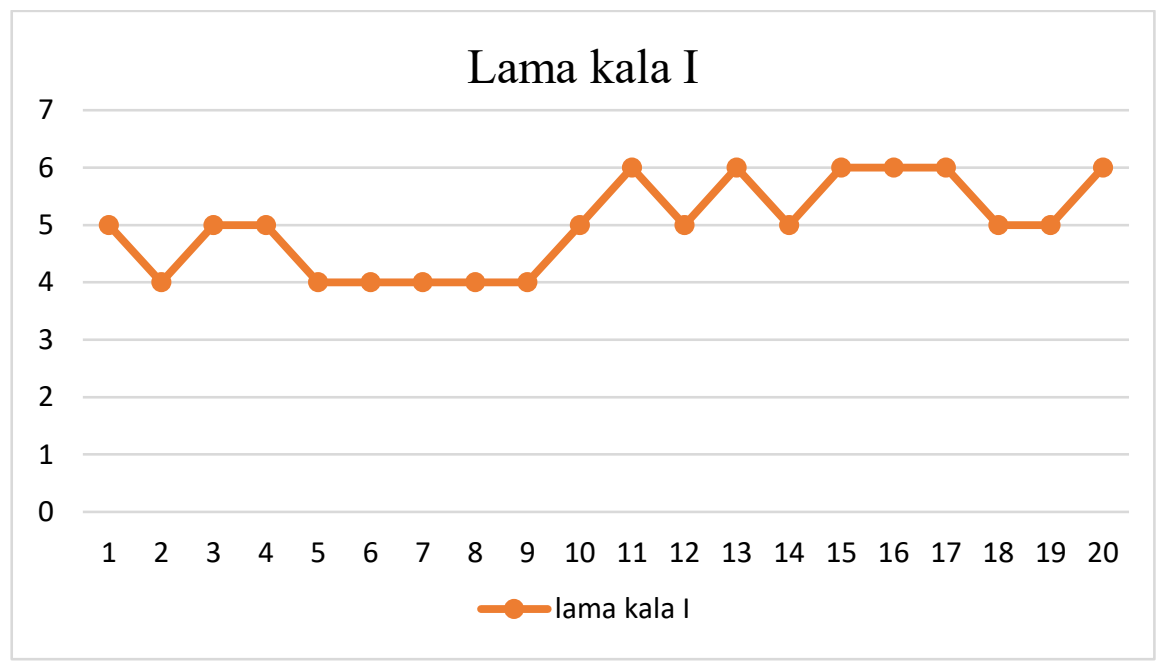

Gambar. 1

Tren Lama Kala I Persalinan

Berdasarkan Gambar 1 menunjukkan bahwa lama kala I persalinan fase aktif yang dialami oleh responden ibu bersalin sebanyak $6(30 \%)$ orang dengan lama kala I persalinan fase aktif selama 4 jam, sebanyak 8 orang
(40\%) dengan kala I fase aktif selama 5 jam dan sebanyak 6 orang (30\%) dengan kala I fase aktif selama 6 jam. 


\section{Pembahasan}

Usia ibu merupakan salah satu faktor risiko yang berhubungan dengan kualitas kehamilan atau berkaitan dengan kesiapan ibu dalam reproduksi. faktor ibu yang memperbesar risiko kematian perinatal (high risk moteur) adalah pada ibu dengan umur lebih tua. Ibu primitua yaitu primigravida yang berumur di atas 35 tahun. Sering ditemui perineum yang kaku dan tidak elastis, hal tersebut akan menghambat persalinan kala II dan dapat meningkatkan risiko terhadap janin. Usia reproduksi sehat adalah 20 tahun sampai 35 tahun. Faktor umur disebut-sebut sebagai penyebab dan predisposisi terjadinya berbagai komplikasi yang terjadi pada kehamilan dan persalinan, antara lain penyebab kelainan his, atonia uteri, plasenta previa dan lain-lain $[17,18]$. Persalinan lama terutama pada primipara biasanya belum atau kurangnya persiapan perhatian dalam mengahadapi persalinan $[18,19]$.

Acupresur juga dapat merangsang pelepaskan oksitosin dari kelenjar hipofisis, yang secara langsung merangsang kontraksi rahim. Karena itu jika proses persalinan lambat, kontraksi lemah dan leher rahim lambat untuk membesar, merangsang acupoint dapat membantu mengatur kontaksi dan mengembalikan keseimbangan untuk proses persalinan [20]. Berdasarkan hasil penelitian dari 20 responden dapat diketahui bahwa lama persalinan kala I fase aktif mendapatkan hasil responden yang diberikan tindakan Akupresur pada titik SP6\&BL67 mendapatkan nilai mean 5,0 dengan rentang lama kala I adalah 4- 6 jam. Dan mengalami percepatan waktu bersalin 1- 2 jam. Hal ini didukung dengan penelitian yang dilakukan di Garut pada tahun 2011 bahwa lama kala I persalinan dengan acupressure Sp6\&B167 mengalami percepatan $<6$ jam [21].

Titik SP6 disebut juga dengan san yin jiao adalah saluran yang berjalan dermatomic L2 dan L1 kemudian menuju T12 dan T5. Saraf simpatik pengendalian rahim melalui pleksus pelvis menerima serat preganglionik keluar dari T5 ke T4 sehingga perangsangan pada titik akupresur ini dapat merubah fungsi fisiologi dari rahim. Letak titik Sp6 adalah 3 cun (4 jari) diatas mata kaki bagian dalam, dipijat searah jarum jam [22,23]. Penelitian ini senada dengan penelitian yang dilakukan di kota Semarang pada tahun 2018 yang menyatakan bahwa titik meridian SP6 dapat merangsang kontraksi uterus yang akan mempercepat lamanya proses persalinan dimana durasi, frekuensi dan interval dari his semakin meningkat setelah dilakukan accupresure pada titik SP6 [24].

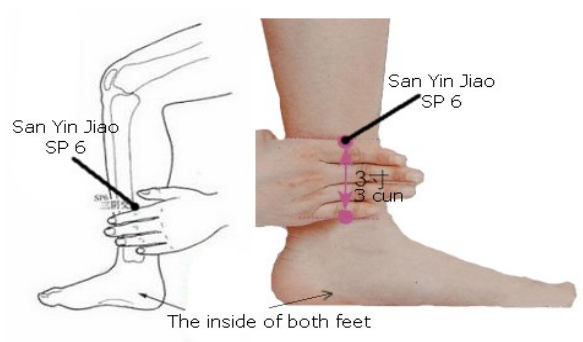

Gambar 2

Letak titik SP6 atau titik limpa[25]

Titik BL67 dikenal sebagai Zhiyin, titik kandung kemih 67 (BL67) dipercaya dapat mengubah posisi janin dan merangsang kontraksi rahim [15,22,26]. Titik BL67 terletak di bagian kaki, tepatnya di luar ujung 
jari kelingking dan dekat dengan tepi kuku kaki [15].

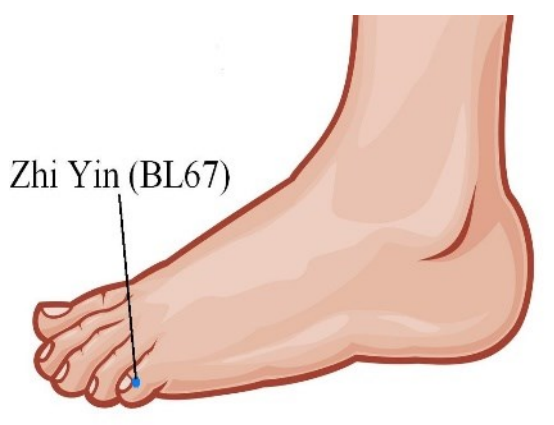

Gambar 3

letak titik BL67 atau kantung kemih[27]

Akupresur pada titik SP 6 memiliki pengaruh yang kuat pada organ reproduksi. Stimulasi pada titik ini dapat meningkatkan konsentrasi energi yin yang bias memulai kerja. Efek dari energi Yin akupresur bias meningkatkan kontraksi uterus karena telah ditunjukkanuntuk meningkatkan hormon oksitosin. Selama persalinan, di sana terjadi penyumbatan meridian yang menyebabkan terhambatnya aliran meridian mengalir melalui tubuh. Stimulus pada titik SP 6 atau LI 4 dapat membuka penyumbatan dan memfasilitasi meridian mengalir. Ini juga membuat ibu lebih tenang saat persalinan. Stimulus pada titik ini juga dapat meningkatkan hormone oksitosin dari kelenjar hipofisis yang menyebabkan peningkatan kontraksi uterus selama persalinan [24].

Pada fase aktif persalinan, frekuensi dan lama kontraksi uterus umumnya meningkat (kontraksi dianggap adekuat jika terjadi tiga kali atau lebih dalam waktu 10 menit dan berlangsung selama 40 detik atau lebih) dan terjadi penurunan bagian terbawah janin. Berdasarkan kurve friedman, diperhitungkan pembukaan pada primigravida $1 \mathrm{~cm} / \mathrm{jam}$ dan pembukaan multigravida $2 \mathrm{~cm} / \mathrm{jam}$ [28].

\section{SIMPULAN}

Penelitian ini menunjukan bahwa accupresure pada titik meridian Sp6 dan BL 67 terbukti dapat mempercepat 1-2 jam lama persalinan kala I fase aktif pada primipara. Accupressure pada titik meridian Sp6 dan BL 67 dapat dilakukan guna merangsang terjadinya kontraksi uterus secara alami dan membuat ibu bersalin merasa nyaman serta rileks dengan adanya penekanan pada titik meridian tersebut sehingga kejadian partus lama dapat dihindarkan.

\section{DAFTAR PUSTAKA}

[1] Astuti HP. Buku Ajar Asuhan Kebidanan Ibu I (Kehamilan). Rohima Pres, Yogyakarta. 2012;268.

[2] Sondakh J. Asuhan Kebidanan Persalinan dan Bayi Baru Lahir. Jakarta: Erlangga. 2013.

[3] Walyani ES, Purwoastuti E. Asuhan Kebidanan Persalinan dan bayi baru lahir. Yogyakarta: Pustaka Baru Press; 2016.

[4] Organization WH. World health statistics 2018: Monitoring health for the SDGs (sustainable development goals). Geneva: World Health Organization. 2018.

[5] Organization WH, UNICEF. Trends in maternal mortality: 1990-2018: estimates from WHO, UNICEF, UNFPA, World Bank Group and the United Nations Population Division. 2018.

[6] Indonesia KR. Profil kesehatan Indonesia tahun 2017. 2017.

[7] Organization. WH. Maternal mortality: World Health Organization. ; 2017 [Available from: https://www.who.int/en/newsroom/fact-sheets/detail/maternalmortality.

[8] Ardhiyanti Y, Susanti S. Faktor Ibu yang Berhubungan dengan Kejadian Persalinan Lama di RSUD Arifin 
Achmad Pekanbaru. Jurnal Kesehatan Komunitas. 2016;3(2):83-7.

[9] Prawirohardjo S. Ilmu Kebidanan Sarwono Prawirohardjo. Jakarta: PT Bina Pustaka2010.

[10] Lowdermilk D, Jensen M, Perry S. Buku Ajar Keperawatan Maternitas Edisi 4. Alih bahasa: Maria \& Peter. Jakarta: EGC; 2013.

[11] Sulistyawati A, Nugraheny E. Asuhan kebidanan pada ibu bersalin. Jakarta: Salemba Medika2010. p. 4.

[12] Rahmawati DT, Iswari I. Efektivitas Akupresur Selama Persalinan. Jurnal Ilmiah Bidan. 2016;1(2):14-8.

[13] Budiarti KD. Hubungan akupresur dengan tingkat nyeri dan lama persalinan kala I pada ibu primipara di Garut. Universitas Indonesia. 2011.

[14] Lathifah NS, Iqmy LO. Pengaruh L14 terhadap Peningkatan Kontraksi pada Kala I Persalinan. Jurnal Kesehatan. 2018;9(3):433-8.

[15] Mollart LJ, Adam J, Foureur M. Impact of acupressure on onset of labour and labour duration: A systematic review. Women and Birth. 2015;28(3):199-206.

[16] Akbarzadeh M, Moradi Z, Jowkar A, Zare N, Hadianfard MJ. Comparing the effects of acupressure at the Jian Jing-Gall Bladder Meridian (GB-21) point on the severity of labor pain, duration and cesarean rate in monoand bi-stage interventions. Women's Health Bulletin. 2015;2(1).

[17] Manuaba IBG, Manuaba I, Manuaba IBG. Ilmu Kebidanan, Penyakit Kandungan dan KB untuk Pendidikan Bidan. Jakarta: EGC. 2010:421-4.

[18] Wiknjosastro GH. Ilmu kebidanan sarwono prawirohardjo. PT Bina Pustaka Sarwono Prawirohardjo, Jakarta. 2010.

[19] RI K. Pelayanan Kesehatan Ibu di Fasilitas Kesehatan Dasar dan Rujukan2013.

[20] Nwanodi OB. Labor pain treated with acupuncture or acupressure. Chinese Medicine. 2016;7(4):133-52.

[21] Budiarti KD. Hubungan akupresur dengan tingkat nyeri dan lama persalinan kala I pada ibu primipara di Garut. Jakarta: Universitas Indonesia. 2011.

[22] Asadi N, Maharlouei N, Khalili A, Darabi Y, Davoodi S, Shahraki HR, et al. Effects of LI-4 and SP-6 acupuncture on labor pain, cortisol level and duration of labor. Journal of acupuncture and meridian studies. 2015;8(5):249-54.

[23] Fatmawati DA. Pengaruh Akupresur Pada Titik Sanyinjiau Terhadap Penurunan Intensitas Nyeri Persalinan Kala I Fase Aktif. Keperawatan. 2018;6(2).

[24] Wardani CK, Widyawati MN, Suryono S. The effectiveness of acupressure at LI 4 and SP 6 point on uterine contraction in the first stage of labor on primiparous women. Indian Journal of Public Health Research \& Development. 2018;9(11):565-70.

[25] Lewis PC. sanyanjiao SP 62017 [Available from: https://images.app.goo.gl/SzJ88ye3C Hk7fmyMA.

[26] Mukhoirotin M, Fatmawati DA. Pengaruh Akupresur Pada Titik Sanyinjiau Terhadap Penurunan Intensitas Nyeri Persalinan Kala I Fase Aktif. Jurnal Keperawatan. 2017;6(2).

[27] sanchez r. zhi yin $B L \quad 672017$ [Available from: https://images.app.goo.gl/zXT5CdTE 9ted5HZ37.

[28] Rohani D. Asuhan Kebidanan Pada Masa Persalinan. Jakarta: Salemba Medika2011. 
Sa'adah Mujahidah \& Novita Sari 